Report No. BMI-1228

UC-25 Metallurgy and Ceramics

(TID-4500, 13th Ed. , Suppl.)

Contract No. W-7405-eng-92

VAPOR DEPOSITION OF MOLYBDENUM AND NIOBIUM COATINGS ON STAINLESS STEEL TUBES

by

Carroll F. Powell

Danny M. Rosenbaum

Robert B. Palmer

Ivor E. Campbell

October 2, 1957

\author{
BATTELLE MEMORIAL INSTITUTE \\ 505 King Avenue \\ Columbus 1, Ohio
}




\section{DISCLAIMER}

This report was prepared as an account of work sponsored by an agency of the United States Government. Neither the United States Government nor any agency Thereof, nor any of their employees, makes any warranty, express or implied, or assumes any legal liability or responsibility for the accuracy, completeness, or usefulness of any information, apparatus, product, or process disclosed, or represents that its use would not infringe privately owned rights. Reference herein to any specific commercial product, process, or service by trade name, trademark, manufacturer, or otherwise does not necessarily constitute or imply its endorsement, recommendation, or favoring by the United States Government or any agency thereof. The views and opinions of authors expressed herein do not necessarily state or reflect those of the United States Government or any agency thereof. 


\section{DISCLAIMER}

Portions of this document may be illegible in electronic image products. Images are produced from the best available original document. 


\section{TAB LE OF CONTENTS}

$\underline{\text { Page }}$

ABSTRACT .............................. 1

INTRODUCTION . . . . . . . . . . . . . . . . . . . . 1

EXPERIMENTAL WORK . . . . . . . . . . . . . . . . . . . 2

Reagents. . . . . . . . . . . . . . . . . . . . . . . 2

External Coatings on Small-Bore Tubing . . . . . . . . . . . . . 2

Internal Coatings on Small-Bore Tubing . . . . . . . . . . . . 4

CONCLUSIONS . . . . . . . . . . . . . . . . . . . . . . . 7

REFERENCE . . . . . . . . . . . . . . . . . . . . . 7 


\title{
VAPOR DEPOSITION OF MOLYBDENUM AND NIOBIUM COATINGS ON STAINLESS STEEL TUBES
}

\author{
Carroll F. Powell, Danny M. Rosenbaum, Robert B. Palmer, \\ and Ivor E. Campbell
}

\begin{abstract}
Apparatus was developed for vapor depositing molybdenum on the outside 7 of 0.1835-in.-OD by 20-in.-long Type 304 stainless steel tubing by hydrogen reduction of molybdenum pentachloride or by thermal decomposition of molybdenum hexacarbonyl, both processes being carried out at reduced pressure. The coatings obtained were uniform, but quite brittle. Apparatus also u as developed for vapor depositing niobium on the inside of the above-mentioned tubing by hydrogen reduction of niobium pentachloride at reduced pressure. These coatings uere uniform, adherent, nonporous, and moderately ductile. 'f 'iutr:,
\end{abstract}

\section{INTRODUC TION}

Certain types of proposed nuclear reactors involve the use of slender uranium rods sealed, along with sodium metal, inside of tubes of Type 304 stainless steel. The tubes are approximately $20 \mathrm{in}$. long and 0.1580 to $0.1585 \mathrm{in}$. in ID, with an 0.008 -in. wall. At the temperatures at which these elements operate in the pile, slow interdiffusion of the uranium and iron occurs at the spots where the uranium rod contacts the tube wall. This eventually results in burnthrough of the tube wall, with loss of the sodium contained within the tube and contamination of the liquid-sodium cooling bath outside of the tube. To provide a greater safety factor against tube failure, and to permit higher operating temperatures in the liquid-sodium coolant, Argonne National Laboratory desires to use a tube material, or a tube lining, which has greater resistance to deterioration by uranium. Molybdenum and niobium are two metals which have satisfactory nuclear properties, and, at the beginning of this development program, appeared to have better resistance to deterioration by uranium than did Type 304 stainless steel. Smallbore thin-walled tubing of niobium or molybdenum is difficult to fabricate, however, and the finished tubes are expensive.

Stainless tubes bearing molybdenum or niobium coatings would be nearly as satisfactory as solid tubes of these latter metals, if an inexpensive method of applying uniform and adherent coatings to the stainless tubes could be developed.

At the start, development of satisfactory processes for internally coating the small-bore tubing did not appear to be feasible because of the very large length-todiameter ratio of over $125 / 1$, and the relative inaccessibility of the interior of the tube to injection nozzles due to the small internal diameter (0.158 in.). Previous work on applying vapor-deposited coatings to the inside of tubing had been confined to tubing having length-to-diameter ratios of less than 50/1, and to internal diameters of $0.5 \mathrm{in}$. or larger, in which injection nozzles for the coating vapor could be placed. Even so, the application of uniform coatings to the inside of these larger, relatively shorter tubes had proved to be difficult. 
The first phase of work in the original contract called for the development of processes for vapor depositing uniform, 0.001 to 0.002 -in. - thick coatings of molybdenum on the outside of the small-bore Type 304 stainless tubing. Upon completion of the first phase, the coating process was to be modified to permit the application of uniform, 0.001 to 0.002 -in. -thick coatings of molybdenum to the inside of the small-bore tubing. Before the problem of coating the inside of the tubing was solved, tests at ANL indicated that molybdenum would not provide the desired degree of improvement in tube life. The objective of the latter part of this development program accordingly was changed to the coating of Type 304 stainless steel tubes on the inside with 0.001 to 0.002 in. of uniform, adherent niobium coatings.

\section{EXPERIMENTAL WORK}

\section{$\underline{\text { Reagents }}$}

The hydrogen used as reducing agent for molybdenum pentachloride and niobium pentachloride, and as carrier gas for molybdenum hexacarbonyl in the carbonyldecomposition plating process was purified by passage through a Deoxo catalytic purifier and then through a cold trap at $-78 \mathrm{C}$.

Linde Standard Grade argon, containing, on the average, less than 5 ppm of nitrogen, less than 4 ppm of oxygen, and less than 3 ppm of carbon-bearing gas, was given no further purification other than passage through a cold trap at $-78 \mathrm{C}$. Gas flows were measured with a variable-area flowmeter.

Molybdenum pentachloride, when used separately, was prepared by treating molybdenum sheet scrap with dry hydrogen at $900 \mathrm{C}$ for about $2 \mathrm{hr}$, then chlorinating with tank chlorine at about 400 to $450 \mathrm{C}$. The pentachloride was used as prepared, but was flushed with reversed flow of carrier gas through the vaporizer at 100 to $110 \mathrm{C}$ at the start of a coating run to remove traces of the more volatile molybdenum oxychlorides which were present in the pentachloride.

Niobium pentachloride was prepared by chlorination of niobium metal powder (Shieldalloy Corporation Commercial Grade, 2 w/o tantalum maximum) with tank chlorine at 350 to $450 \mathrm{C}$. Part of this chloride was purified by a single-stage sublimation in vacuo, or in dry argon gas at atmospheric pressure, but most of the coatings were made with the chloride as it came from the chlorinator, where it had been sealed in glass ampules without exposure to air.

Molybdenum hexacarbonyl was obtained from the Climax Molybdenum Company and used without further purification.

\section{External Coatings on Small-Bore Tubing}

Five different types of apparatus were tested for coating the outside of 20-in. lengths of the small-diameter tubing. The most successful was a tank-type coater in which the coating chamber was a cylindrical stainless steel tank having hemispherical 
ends. The tark was $24 \mathrm{in.}$ over-all in length by $12 \mathrm{in.}$ in diameter. A 14-in. -length of 1. 25-in. -OD stainless tubing was welded to the side wall of the tank at its midpoint to serve as a vaporization chamber for the molybdenum pentachloride or hexacarbonyl. Packing glands were attached to the ends of the tank, on its axis. These glands recelved Pyrex gas-outlet tubes into which were fitted copper electrodes to which the specimen tube was attached. All glass-to-metal joints were sealed with neoprene O-rings. The specimen was heated by passing about 40 to $50 \mathrm{amp}$ of electric current through it. The specimen temperature was measured by means of a thermocouple which was inserted inside of the specimen tube, with the leads brought out through the glass end tubes.

The tank-type coater was designed to produce a uniform coating over a long length of tubing by providing space for thorough mixing of the incoming plating vapor with the atmosphere in the plating chamber before it contacted the specimen. This permitted all parts of the specimen to be contacted by the same concentration of plating vapor. Such operation is effective in depositing molybdenum from the carbonyl or pentachloride, where the equilibria for the deposition reaction lie so strongly in the direction of metal deposition that large concentrations of plating by-products (CO from decomposition of the carbonyl or $\mathrm{HCl}$ from hydrogen reduction of the pentachloride) do not appreciably hinder the deposition reaction.

Molybdenum deposition from the hexacarbonyl and pentachloride was carried out at reduced pressure. This was done by exhausting the plating system by means of a Pressovac pump, protected by a liquid-nitrogen trap, to a pressure of about $15 \mu$. $\mathrm{Hy}-$ drogen was then bled into the vaporizer, containing molybdenum hexacarbonyl or molybdenum pentachloride, through a capillary tube and stopcock. The specimen was heated to coating temperature in a slow flow of hydrogen, the vaporizer remaining cold $(-70 \mathrm{C}$ in the case of molybdenum hexacarbonyl, room temperature in the case of molybdenum pentachloride) while the specimen was being heated. The vaporizer was then warmed to produce the desired partial pressure of hexacarbonyl or pentachloride vapor. At the end of the coating period the vaporizer was cooled and the specimen cooled in pure hydrogen at low pressure. When coating with molybdenum from the hexacarbonyl, the tank walls were cooled with a water spray to prevent carbonyl decomposition at the walls. When depositing from the hexachloride, the tank walls were insulated with glass wool to enable radiation from the specimen to heat them above the condensation temperature of the hexachloride vapor.

The specimens, 21-in. lengths of 0.1835-in. -OD 0.010-in. wall Type 304 stainless tubing, were cleaned by degreasing with acetone before being loaded into the coating unit.

No satisfactory molybdenum coatings were obtained from molybdenum hexacarbonyl in the tank coater at specimen temperatures of $930,700,550,525$ or $300 \mathrm{C}$ or with combinations of these temperatures. Total pressures of 0.5 to $2 \mathrm{~mm}$ of mercury, and carbonyl vaporization temperatures ranging from 40 to $105 \mathrm{C}$ were tried. All the molybdenum coatings obtained were brittle and poorly adherent, although they were uniform. The heavier coatings usually spalled from the specimen spontaneously due to the stresses created when the tube cooled from coating temperature. The use of wet hydrogen as carrier gas for the hexacarbonyl at a deposition temperature of 525 to $530 \mathrm{C}$ and a total pressure of $0.6 \mathrm{~mm}$ of mercury did not improve coating ductility, and caused formation of a thin oxide film between the molybdenum coating and the stainless tube. The heaviest coating obtained had a thickness of $1.9 \mathrm{mils}$ at the center of the tube and 1.6 mils at either end of the tube. 
Molybdenum deposition from the pentachloride was investigated only briefly in the tank coater. The deposit obtained at a specimen temperature of $900 \mathrm{C}$ and at a total pressure of $4 \mathrm{~mm}$ of mercury was brittle and poorly adherent. The coating thickness obtained in a $2-\mathrm{hr}$ coating period ranged from 0.4 to $0.45 \mathrm{mil}$ on the center of the specimen to 0.3 to $0.35 \mathrm{mil}$ on the ends of the specimen.

Niobium deposition in the tank-type coater was not tried, but there is no reason to believe that highly uniform, ductile niobium deposits could not be obtained on the outside of the specimens in this coater. However, the moving-temperature-gradient coating unit proved to be more versatile in that the outside and inside surfaces of the tubing could be coated simultaneously if necessary.

\section{Internal Coatings on Small-Bore Tubing}

Four different types of apparatus for coating the inside of the small-bore tubing were tested. Only one proved capable of doing the job. This was the movingtemperature-gradient coater, of which several versions were tried. In this type of coating unit, the specimen was heated uniformly to deposition temperature by means of a resistance furnace having a tapped winding. A mixture of hydrogen and metal halide vapor was passed through the tube while the tapped furnace windings were slowly shorted or shunted out by external resistances so that a temperature of about $200 \mathrm{C}$, just high enough to prevent condensation of the metal halide, was produced in the shunted furnace section. The shunting of the furnace coils started at the gas-inlet end of the plating tube and progressively moved to the gas-exit end. This produced a $200 \mathrm{C}$ temperature zone moving over the specimen from the gas-inlet to the gas-exit end. Since metal deposition took place only within the first inch or two of the hightemperature plating zone, this plating region preceded the temperature gradient from the inlet to the exit end of the tube. By keeping the entire section of the tube downstream from the temperature gradient at the deposition temperature at all times, fouling of the unplated section of the specimen by condensation of less volatile lower halides or other reaction products was avoided. Fouling of the upstream section (the $200 \mathrm{C}$ section) was of no consequence since this section was coated before any fouling could occur (however, no fouling of the $200 \mathrm{C}$ upstream section was observed when depositing niobium). Moving-temperature-gradient coating units were constructed of stainless steel for durability, but were found to give a less sharp temperature gradient than units constructed of Vycor or fused-silica glass. It was found possible to coat the inside and outside surfaces of a specimen simultaneously in one of these units by designing it so that the annular space between the specimen and the coating-tube wall had the same friction factor (i.e., hydraulic radius) as the circular space inside of the specimen.

The final coating unit, in which most of the coatings were made, was constructed of Vycor and fused-silica tubing, and could treat seven specimens at one time, assembled into a compact bundle which fitted snugly insice of the 9/16-in. -ID fused-silica deposition tube. Because of the small amount of space left around the outside of the specimens by this arrangement, 90 per cent or better of the metal deposited was applied to the inside surfaces of the specimens. The coating tube was heated by a 24-in. -long by 0.75 -in. -ID Chromel-wound furnace. This heating element was divided into sixteen 1.5-in.-long sections by fifteen taps. Each section was connected in parallel with an external resistance coil through a microswitch. A motor-driven tripper closed these microswitches at fixed intervals to bypass the furnace coil and thus reduce the heating current through that particular coil. A second group of external resistances was 
mounted in series with the furnace element. Each member of this series of resistance. was connected to a microswitch which shorted out the resistance when closed. This second series of microswitches was opened by the same tripper which closed the microswitches in the furnace bypass series, thus throwing enough additional resistance into the circuit to compensate for the reduced resistance of the bypassed furnace elements. This permitted operation of the coating unit on a constant voltage.

The vaporizer section of the coater consisted of a 28-in. -length of 30-mm Vycor tubing attached to the top end of the silica deposition tube. The open end of the vaporizer tube terminated in a 29/42 standard-taper Vycor joint which was closed with a mating joint of Pyrex bearing the hydrogen-inlet tube. The 1-in.-diameter sealed ampules of niobium pentachloride were inserted in the vaporizer section and their seals broken with a pointed rod after the entire coating unit had been flushed with dry argon gas. The vaporizer section was heated by a 24-in. -long untapped sleeve heater. The vaporizer temperature was determined by means of a thermocouple placed between the heater wall and the outside wall of the vaporizer tube.

With a constant gas-flow rate and a constant temperature in the plating zone, uniformity of deposition depended only on the constancy of the metal halide-vaporization rate. Since the surface area of metal halide exposed to the carrier-gas stream slowly decreased during a run due to depletion and compaction of the halide, the deposition rate also decreased. This was compensated for by slowly increasing the vaporizer temperature during the run. This increase was effected by a third group of resistances mounted in series with the vaporizer heater. These resistances were progressively shorted out by a third series of microswitches actuated by the same tripper which operated the other two series of switches. The amount of temperature rise required in the vaporizer to give a constant vaporization rate was determined by trial and error. In its final form, a slight amount of overcorrection existed so that the plate deposited on the terminal end of the specimen was slightly heavier than that deposited on the starting end. The whole operation of the coating unit was entirely automatic after being started, including the shutting off of the furnaces and the switching mechanism at the completion of the run. This permitted the unit to be operated with a minimum of attention. The temperatures inside the plating zone and the vaporizer chamber were determined from a blank run in the empty coating unit, with thermocouples inserted inside of the unit. Temperature versus heater current was recorded.

The specimens were 21 -in. lengths of Type 304 stainless tubing, 0.1580 to $0.1585 \mathrm{in}$. in ID with an 0.008 -in. wall, or 0.1635 in. in ID with a $0.010-$ in. wall. These were cleaned by blowing pipe cleaners through them to remove dirt and filings, then degreasing with acetone and drying with warm air.

In a number of runs where single tubes were coated, the specimens were etched in warm, dilute hydrochloric acid, and then given a 0.0002 to 0.0005-in. - thick coating of chemically (electroless) deposited nickel inside and out before being coated with niobium (a buffered, alkaline hypophosphite bath (J. Electrochem. Soc. 104, 227 (1957) gave the best nickel coatings). (1) The nickel flash appeared to improve slightly the adhesion of the niobium coatings. However, these nickel coatings contained enough phosphorus ( 3 to $11 \mathrm{w} / \mathrm{o}$ ) to lower their fusion temperature to around 880 to $900 \mathrm{C}$. When deposition temperatures above $850 \mathrm{C}$ were used, relatively rapid diffusion of the nickel layer into the basis metal or the niobium coating occurred. When bundles of

(1) Reference at end. 
specimen tubes having the nickel layer were coated with niobium at temperatures above $900 \mathrm{C}$, fusion of the nickel layer resulted in welding of the tubes to each other. For these reasons, use of the nickel intermediate layer was discontinued.

Niobium was deposited in this coating unit by hydrogen reduction of niobium pentachloride at reduced pressure in the manner previously described for molybdenum deposition in the tank coater (hydrogen being bled into the evacuated system through a capillary tube and stopcock).

The following conditions were found to produce uniform, adherent coatings in the moving-temperature-gradient-coater: specimen temperature, $1000 \mathrm{C}$; niobium pentachloride temperature, 128 to $155 \mathrm{C}$ (range covered from the beginning to the end of the coating period); hydrogen-flow rate, $180 \mathrm{~cm}^{3}$ per min, STP; total pressure in coating chamber, about $5 \mathrm{~mm}$ of mercury; total deposition period, $16 \mathrm{hr}$ for a $1.4-\mathrm{mil}$-thick coating, $8 \mathrm{hr}$ for a 0.6 to 0.7 -mil-thick coating; deposition period for each section of tube (for each tap on the heater), $1 \mathrm{hr}$ for a 1.4 -mil-thick coating, $1 / 2 \mathrm{hr}$ for a 0.6 to 0.7 -mil-thick coating.

A specimen temperature of $850 \mathrm{C}$ produced black, brittle coatings, and lower hydrogen flow rates $\left(60\right.$ to $120 \mathrm{~cm}^{3}$ per min) resulted in incomplete reduction of the niobium pentachloride. The coatings obtained at $1000 \mathrm{C}$ were usually ductile enough to permit the tube to be slit and opened out without cracking or spalling the coating.

Coating thicknesses were determined from the weight of metal deposited, by sectioning and polishing several portions of the coated tube and examining the cross section microscopically, and by dissolving away the stainless steel basis metal in dilute hydrochloric acid and measuring the thickness of the niobium metal flakes left as residue. This last method was somewhat difficult because of the nonporosity of the niobium coatings which were over $0.5 \mathrm{mil}$ thick. The coating thicknesses obtained by the three methods were in good agreement.

Coating uniformity was determined from the microscopic examination and also from radiographs of entire specimens. The latter showed that some batches of coated tubes had short-range variations in coating thickness which appeared to be caused by fluctuations in the niobium pentachloride vaporization rate. The cause of these fluctuations was not determined. The tubes in Batch 17 (1.4-mil-thick coating) appeared to have less than 10 per cent variation in coating thickness over a 20-in. length of tubing. Batches 15 (0.6-mil average coating), 16 (1.4-mil average coating), and 20 (1.3-mil average coating) appeared to have greater nonuniformity, ranging from 20 to 50 per cent of the average coating thickness.

The niobium coatings on one representative batch (Batch 15) had a Vickers hardness of 160 to $180 \mathrm{~kg}$ per $\mathrm{mm}^{2}$. This is harder than the purest riobium that can be obtained by hydrogen reduction of the pentachloride, but the coating was still sufficiently ductile to permit the tube to be slit and spread open without cracking or spalling the coating.

The deposition efficiency, as measured by the ratio of weight of metal deposited in the specimens to weight of metal vaporized as niobium pentachloride, ranged from 63 to 75 per cent. The rate of production with the seven-tube moving-temperaturegradient coater at the end of this research program was about 25 to 30 coated tubes per month. On this basis, the cost of the coating per tube was about $\$ 80.00$ to $\$ 100.00$. It 
is considered to be reasonably certain that the capacity of the moving-temperaturegradient coater could be increased to perhaps 100 specimens per run by a modest increase in the size of the apparatus, and the cost of niobium coating brought down to around $\$ 3.00$ per tube.

\section{CONCLUSIONS}

A moving-temperature-gradient vapor plating unit has been developed in which numbers of long, small-diameter tubing can be coated uniformly at one time with niobium, either on the inside surfaces, or on the outside surfaces, or on both surfaces simultaneously. The niobium coatings obtained on the inside of Type 304 stainless steel tubes were nonporous, adherent, and sufficiently ductile to permit considerable deformation of the coated tube without damage to the coating. The cost of applying these coatings ranged around $\$ 80.00$ to $\$ 100.00$ per tube at the conclusion of this work program. It is believed that this cost can be brought down to around $\$ 3.00$ per tube by an increase in the size of the apparatus and by further standardization of the coating procedure. This same coating unit should be suitable for applying coatings of other metals, such as tantalum or molybdenum, to long lengths of small-bore tubing.

\section{REFERENCE}

(1) Sullivan, M. V., and Eigler, J. H., "Electroless Nickel Plating for Making Ohmic Contacts to Silicon", J. Electrochem. Soc., 104, 227 (1957).

CFP/DMR/RBP/IEC:pa 